\title{
Algorithm for Detecting, Indentifying, Locating and Experience to Develop the Automate Faults Location in Radial Distribution System
}

\author{
Choowong-Wattanasakpubal ${ }^{\dagger}$ and Teratum-Bunyagul* $^{*}$
}

\begin{abstract}
This paper presents the design of an algorithm to detect, identify, and locate faults in radial distribution feeders of Provincial Electricity Authority (PEA). The algorithm consists of three major steps. First, the adaptive algorithm is applied to track/estimate the system electrical parameter, i.e. current phasor, voltage phasor, and impedance. Next process, the impedance rule base is used to detect and identify the type of fault. Finally, the current compensation technique and a geographic information system (GIS) are applied to evaluate a possible fault location. The paper also shows the results from field tests of the automate fault location and illustrates the effectiveness of the proposed fault location scheme.
\end{abstract}

Keywords: Fault location, Fault diagnosis, Fault detection, Distribution

\section{Introduction}

Fast and accurate determination of a fault location in electrical power system is a vital part in power restoration. A range of fault location techniques have been proposed in many literatures [1]-[3]. However, they were mainly developed for transmission systems. The methods can be divided into two categories, which are based on travelling waves and based on impedance calculation seen from the line terminal and estimate the distance of fault. Nonetheless, very few methods were proposed for distribution networks due to the following reasons.

Variety of configuration: Typical distribution feeders are arranged in various configurations. As a result, there is no linear relationship between line impedance and a distance between a fault location and a substation.

Branch lines: Unlike transmission-line s, typical distribution feeders have several lateral branches. The fault location procedure may result in several points of possible locations.

Distributed load along the feeder: The current measured at a substation during fault occurrence is a sum of load currents at each node. In contrast to transmission systems, fault current in the distribution system is fairly low comparing with load current. Consequently, it is impossible to accurately determine fault current.

Incorrect fault type identification: Impedance-based fault locating methods require fundamental voltage and current quantities corresponding to the fault for calculating for fault locations from the apparent impedance. According to field tests data, it is found that most of faults in PEA's distribution system are started as a single line to ground fault. Then, it can develop into other types, e.g. double line

$\dagger \quad$ Corresponding Author: Research Division of Provincial Electricity Authority (PEA), Thailand. (d_power_system@hotmail.com)

* Department of Electrical Engineering, King Mongkut's University of Technology North Bangkok, Thailand. (teratam@kmutnb.ac.th)

Received : September 7, 2009; Accepted : December 14, 2009 to ground fault. As a result, to improve the accuracy and ability of automated distribution system fault locator the algorithm should be able to track the change in type of fault types.

Extract Phasor: Accurate tracking of the instantaneous phasor in power-disturbance waveforms is the most essential function of the automate fault location. There are special conditions in a power system, e.g., small frequency deviation, distortion of voltage and current waveforms from arcing fault, requirements with regards to accuracy, which have to be taken into consideration.

Basically, there are two different approaches for locating faults in distribution system. One is based on the algorithms that use measurements of voltage and current signals from a fault recorder at a substation [4]-[6]. The latter is based on fault detectors installed along a feeder [7]. Both approaches can combine to determinate the position of fault in distribution feeders. For example, the scheme is used to determinate possible fault locations in the main line, while fault detectors at lateral branches are applied to locate possible fault locations between main and lateral line.

Provincial Electricity Authority (PEA) in Thailand is responsible for supplying electricity to the customers in 73 provinces. PEA service areas account for $99 \%$ of the territory. The procedure to identify fault location of PEA is still based on customer calls, line visual inspection and trial and error method. After receiving customer calls feeder maps and protection design manuals will be used to identify an outage area. Afterward, the crews are sent out to fix the problems. As can be seen, fault locating in this manner is time-consuming.

This paper is concerned with the design of a new algorithm to detect, identify and locate faults on-inhomogeneous distribution feeders of PEA. The algorithm is based on the previous work [8]-[11] and applied the following techniques:

1. A new adaptive algorithm is used to track dynamic voltage-current phasor, and frequency of the power system 
[8]-[9]. The accuracy of this algorithm in tracking orthogonal coefficients and real-time frequency is very high. Besides, it is easy to implement.

2. The new fault classification index (FI) and impedance rules based are used to detect and identify the type of fault. The performance of this module is fast and robust. The module detects and classifies a fault type within 3.8 ms using a low sampling rate at 16 samples per cycle.

3. The algorithm applies one-ended method to calculate the apparent reactance.

4. The fault boundary factor $(\mathrm{K})$ represents possible faulted areas. In real situation, the only information available is where to start and to stop searching.

5. Geographic Information System (GIS) provides information about network topology and electrical parameters. The implementation of the algorithm is fairly easy by using a set of computer with a data acquisition board inside. In addition, the algorithm reduces errors caused by load current, fault resistance and incorrect fault type identification.

The paper also shows the obtained results from the field test of the automated fault location system employing the techniques mentioned above. This system integrates the information of feeder configuration and geographic information system (GIS). The service restoration process will be significantly sped up.

The method proposed by [12] describes a fault location algorithm based on the voltage and current input signals provided by digital disturbance recorders installed at the substations. The fault location algorithm uses the symmetrical components of the voltage and current phasor quantities derived from these records. Fault location system based on artificial intelligence methods (fuzzy logic) [6], [13]. Nonetheless, the proposed system requires a large set of information which are short-circuit currents information provided by fault detection devices installed along the feeders. The estimation of a fault distance is obtained from the current measured by the digital over current relays while fault resistance is not considered. As a result, this method will estimate a fault location that, in most cases, is far from the actual one. Other recent efforts have focused on developing fault diagnosis systems using knowledge based approaches [14]-[15]. Knowledge-based techniques often rely on external information, e.g. SCADA alarms, substation and feeder switch status, feeder measurements, load voltage sensors, etc. However, in many distribution systems, knowledge-based approaches may not be feasible since measurements are usually only available at the substation and information about the operation of feeder protective devices are normally unknown.

\section{Design of an Algorithm}

The flow chart in Fig.1 shows fault location and diagnosis scheme that consisting of three sequential processes. The first block is on-line process, the adaptive algorithm used to track voltage-current phasor of the distribution feeder. The second block is on-line process, the impedance rule base used to detect and identify the type of fault. After fault was detected, pre-fault and during fault of voltages signal and currents signal were recorded and alarmed by the automate fault location. The third block, evaluates possible fault locations with one-ended method using fault boundary factor and GIS in off-line process. The following will be explanations of each individual process.

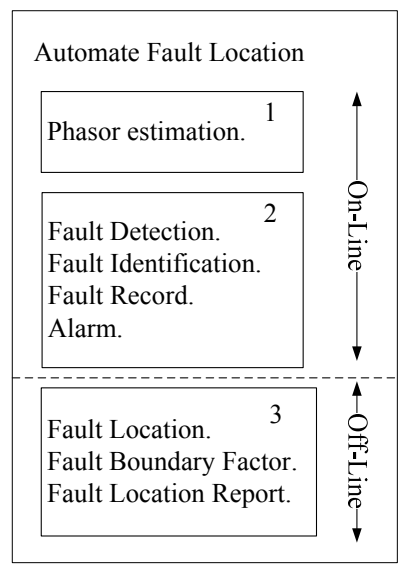

Fig.1. Fault location and diagnosis scheme.

\subsection{Adaptive Algorithm for On-line Tracking Voltage- Current Phasor}

Firstly, the adaptive algorithm is used to track/estimate voltage-current phasor of power system. Fig. 2 illustrates structure of ADALINE for tracking dynamic voltagecurrent phasor and frequency of the power system. The structure is formed by the linear combination of its input vector $\left[\cos \left(\omega_{s} t\right)-\sin \left(\omega_{s} t\right)\right]$ at any given time. The input vector is multiplied by the weighting vector $\left[\mathrm{w}_{1} \mathrm{w}_{2}\right]$ (orthogonal coefficients), and then summed up to produce the linear output $y(t)$.

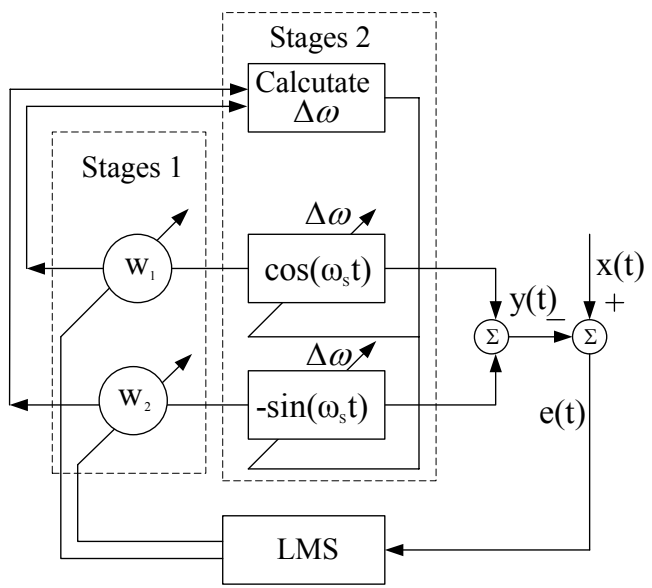

Fig. 2. ADALINE structure for tracking voltage-current phasor. 
The weighting vector can be adjusted using Least Mean Square algorithm (LMS). This will provide output $y(t)$ that is close to the input signal $\mathrm{x}(\mathrm{t})$ (voltage or current signal). Different from other methods, the proposed new algorithm assumes that the phasor and frequency are dynamic. The main procedure is divided into two stages. First, weighting vector is estimated. Then, the angular speed of fundamental frequency of input vector will be adjusted by $\Delta \omega$ to obtain the actual value.

Stages 1: Let assume that the observation model of an input signal (voltage or current) at the measurement location can be expressed as (1).

$$
y(t)=A \cos \left(\theta+\Delta \omega t+\omega_{s} t\right)
$$

Where

A is the magnitude of signal.

$\theta$ is the phase angle.

$\omega_{\mathrm{S}}$ is the angular speed of fundamental frequency.

$\Delta \omega$ is a small change in angular speed of fundamental frequency.

$\mathrm{t}$ is the time of observation.

Applying the trigonometry relationship of $\cos (a+b)=$ $\cos (a) \cdot \cos (b)-\sin (a) \cdot \sin (b)$ to the above equation will result in

$$
\begin{aligned}
y(t) & =A \cos (\theta+\Delta \omega t) \cdot \cos \left(\omega_{s} t\right) \\
& -A \sin (\theta+\Delta \omega t) \cdot \sin \left(\omega_{s} t\right)
\end{aligned}
$$

Equation (2) can be rewritten in a matrix form as following.

$$
\begin{gathered}
\mathrm{X}(\mathrm{t})=\left[\cos \left(\omega_{\mathrm{s}} \mathrm{t}\right)-\sin \left(\omega_{\mathrm{s}} \mathrm{t}\right)\right] \\
\mathrm{w}_{1}=\operatorname{Acos}(\theta+\Delta \omega \mathrm{t}) \\
\mathrm{w}_{2}=A \sin (\theta+\Delta \omega \mathrm{t}) \\
\mathrm{W}(\mathrm{t})=\left[\begin{array}{ll}
\mathrm{w}_{1} & \mathrm{w}_{2}
\end{array}\right] \\
\mathrm{y}(\mathrm{t})=\mathrm{W}(\mathrm{t}) \cdot \mathrm{X}^{\mathrm{t}}(\mathrm{t}) \\
\mathrm{e}(\mathrm{t})=\mathrm{x}(\mathrm{t})-\mathrm{y}(\mathrm{t})
\end{gathered}
$$

Where

$\mathrm{X}(\mathrm{t})$ is the input vector.

$\mathrm{W}(\mathrm{t})$ is the weighting vector representing the orthogonal coefficients of voltage-current.

$\mathrm{w}_{1}$ is the orthogonal coefficient representing a real part of voltage-current phasor.

$\mathrm{w}_{2}$ is the orthogonal coefficient representing an imaginary part of voltage-current phasor.

$y(t)$ is the output signal from the observation model.

$x(t)$ is the input signal (voltage or current).

$\mathrm{k}$ is the index of iteration.

$\alpha \quad$ is the learning parameter.
For discrete-time signal, the weighting vector can be updated by using Widrow-Hoff delta rule as following.

$$
\mathrm{W}(\mathrm{k}+1)=\mathrm{W}(\mathrm{k})+\frac{\alpha \cdot \mathrm{e}(\mathrm{k}) \cdot \mathrm{X}(\mathrm{k})}{\mathrm{X}(\mathrm{k}) \cdot \mathrm{X}^{\mathrm{t}}(\mathrm{k})}
$$

Substituting $X(k) \cdot X^{t}(k)=1$ into (9), one can obtain

$$
\mathrm{W}(\mathrm{k}+1)=\mathrm{W}(\mathrm{k})+\alpha_{1} \cdot \mathrm{e}(\mathrm{k}) \cdot \mathrm{X}(\mathrm{k})
$$

A perfect learning in (10) is completed when the error $\left(|e|^{2}\right)$ is brought to zero. The weighting vector $(\mathrm{W}(\mathrm{k}))$ of voltage and current signal at the measurement location will be represented in phasor or complex form. Therefore, the system can track voltage and current phasor.

Stages 2: A study of previous work has revealed that most of voltage and current phasor estimation are not suitable for extracting the fundamental components. This is because the observation model neglects a small change in angular speed of fundamental frequency $(\Delta \omega)$. In this paper, the effect of $\Delta \omega$ must be considered and being adjusted to its actual value. A small change in angular speed of the fundamental frequency is computed accurately from the weighting vector according to (11).

$$
\Delta \omega=\frac{\mathrm{w}_{1}(\mathrm{k}) \cdot \mathrm{w}_{2}^{\prime}(\mathrm{k})-\mathrm{w}_{2}(\mathrm{k}) \cdot \mathrm{w}_{1}^{\prime}(\mathrm{k})}{\left(\mathrm{w}_{1}^{2}(\mathrm{k})+\mathrm{w}_{2}^{2}(\mathrm{k})\right)}
$$

From (11), $\mathrm{w}_{1}^{\prime}(\mathrm{k})$ and $\mathrm{w}_{2}^{\prime}(\mathrm{k})$ are the derivative of weighting vector respect to time. A differentiation method can be used to compute $\mathrm{w}_{1}^{\prime}(\mathrm{k})$ and $\mathrm{w}_{2}^{\prime}(\mathrm{k})$ according (12) and (13), where $\Delta \mathrm{t}$ is the sampling time interval.

$$
\begin{aligned}
& \mathrm{w}_{1}^{\prime}(\mathrm{k})=\frac{\mathrm{w}_{1}(\mathrm{k})-\mathrm{w}_{1}(\mathrm{k}-1)}{\Delta \mathrm{t}} \\
& \mathrm{w}_{2}^{\prime}(\mathrm{k})=\frac{\mathrm{w}_{2}(\mathrm{k})-\mathrm{w}_{2}(\mathrm{k}-1)}{\Delta \mathrm{t}}
\end{aligned}
$$

For discrete-time signal, the angular speed of the fundamental frequency according to the observation model in (1) can be updated to the actual value by using (14).

$$
\omega_{\mathrm{S}}(\mathrm{k}+1)=\omega_{\mathrm{S}}(\mathrm{k})+\Delta \omega
$$

\subsection{Fault Detection and Fault Type Identification Al- gorithm}

Fault detection is an important step in the fault location procedures. The task of fault detection includes two major parts. The first part is to create fault classification index, using as the indicator. The second part is the design of a decision rule to detect and classify the fault type. The process can be described as follows. The magnitude of phase impedance $\mathrm{a}, \mathrm{b}$ and $\mathrm{c}$ was calculated by applying Ohm's 
law according to (15).

$$
Z_{\mathrm{a}}(\mathrm{k})=\frac{\mathrm{V}_{\mathrm{a}}(\mathrm{k})}{\mathrm{I}_{\mathrm{a}}(\mathrm{k})}, \mathrm{Z}_{\mathrm{b}}(\mathrm{k})=\frac{\mathrm{V}_{\mathrm{b}}(\mathrm{k})}{\mathrm{I}_{\mathrm{b}}(\mathrm{k})}, \mathrm{Z}_{\mathrm{c}}(\mathrm{k})=\frac{\mathrm{V}_{\mathrm{c}}(\mathrm{k})}{\mathrm{I}_{\mathrm{c}}(\mathrm{k})}
$$

Where

$\mathrm{V}_{\mathrm{a}}(\mathrm{k}), \mathrm{V}_{\mathrm{b}}(\mathrm{k})$ and $\mathrm{V}_{\mathrm{c}}(\mathrm{k})$ are the voltage phasor quantities. $\mathrm{I}_{\mathrm{a}}(\mathrm{k}), \mathrm{I}_{\mathrm{b}}(\mathrm{k})$ and $\mathrm{I}_{\mathrm{c}}(\mathrm{k})$ are the current phasor quantities. $Z_{\mathrm{a}}(\mathrm{k}), Z_{\mathrm{b}}(\mathrm{k})$ and $Z_{\mathrm{c}}(\mathrm{k})$ are phase impedance.

The average magnitude of phase impedance $Z_{A}(k)$ can be calculated by using (16) and phase impedance a, b and c can be normalised by using (17) - (19).

$$
\begin{gathered}
Z_{\mathrm{A}}(\mathrm{k})=\frac{Z_{\mathrm{a}}(\mathrm{k})+Z_{\mathrm{b}}(\mathrm{k})+Z_{\mathrm{c}}(\mathrm{k})}{3} \\
\mathrm{Z}_{\mathrm{Na}}(\mathrm{k})=\left|\frac{Z_{\mathrm{a}}(\mathrm{k})}{Z_{\mathrm{A}}(\mathrm{k})}\right| \\
\mathrm{Z}_{\mathrm{Nb}}(\mathrm{k})=\left|\frac{Z_{\mathrm{b}}(\mathrm{k})}{Z_{\mathrm{A}}(\mathrm{k})}\right| \\
\mathrm{Z}_{\mathrm{Nc}}(\mathrm{k})=\left|\frac{Z_{\mathrm{c}}(\mathrm{k})}{Z_{\mathrm{A}}(\mathrm{k})}\right|
\end{gathered}
$$

Where $Z_{\mathrm{Na}}(\mathrm{k}), \mathrm{Z}_{\mathrm{Nb}}(\mathrm{k})$ and $\mathrm{Z}_{\mathrm{Nc}}(\mathrm{k})$ are normalized impedance of phase $a, b$ and $c$.

According to observation and experiment, the values of normalised phase impedance relates to unsymmetrical faults as shown in Table 1. The letter $\mathrm{H}$ means that the normalized impedance of a particular fault type is equal or greater than 1 . In contrast, the letter L means that the normalized impedance is less than 1 . Table 1 gives the interrelationship between the fault types and the position of letter $\mathbf{H}$. It is noticeable that there are three $\mathbf{H s}$ in each fault

\begin{tabular}{|c|c|c|c|c|c|c|}
\hline \multirow[b]{2}{*}{$\begin{array}{c}\text { Normalized } \\
\text { impedance }\end{array}$} & \multicolumn{6}{|c|}{ Fault type } \\
\hline & $a-g$ & b-g & c-g & $\begin{array}{c}a b \\
a b-g\end{array}$ & $\begin{array}{c}\mathrm{ac} \\
\mathrm{ac}-\mathrm{g}\end{array}$ & $\begin{array}{c}\mathrm{bc} \\
\mathrm{bc}-\mathrm{g}\end{array}$ \\
\hline $\mathrm{Z}_{\mathrm{Na}}(\mathrm{k})$ & $\mathrm{L}$ & $\mathrm{H}$ & $\mathrm{H}$ & $\mathrm{L}$ & $\mathrm{L}$ & $\mathrm{H}$ \\
\hline$Z_{\mathrm{Nb}}(\mathrm{k})$ & $\mathrm{H}$ & $\mathrm{L}$ & $\mathrm{H}$ & $\mathrm{L}$ & $\mathrm{H}$ & $\mathrm{L}$ \\
\hline $\mathrm{Z}_{\mathrm{Nc}}(\mathrm{k})$ & $\mathrm{H}$ & $\mathrm{H}$ & $\mathrm{L}$ & $\mathrm{H}$ & $\mathrm{L}$ & $\mathrm{L}$ \\
\hline $1-Z_{\mathrm{Na}}(\mathrm{k})$ & $\mathrm{H}$ & $\mathrm{L}$ & $\mathrm{L}$ & $\mathrm{H}$ & $\mathrm{H}$ & $\mathrm{L}$ \\
\hline $1-Z_{\mathrm{Nb}}(\mathrm{k})$ & $\mathrm{L}$ & $\mathrm{H}$ & $\mathrm{L}$ & $\mathrm{H}$ & $\mathrm{L}$ & $\mathrm{H}$ \\
\hline $1-Z_{\mathrm{Nc}}(\mathrm{k})$ & $\mathrm{L}$ & $\mathrm{L}$ & $\mathrm{H}$ & $\mathrm{L}$ & $\mathrm{H}$ & $\mathrm{H}$ \\
\hline \multicolumn{7}{|c|}{$\begin{array}{l}\text { The letter } \mathbf{H} \text { means the normalized impedance is more than or } \\
\text { equal to } 1 \text {. The letter } \mathbf{L} \text { means the normalized impedance is less } \\
\text { than } 1 \text {. }\end{array}$} \\
\hline
\end{tabular}
type.

As a result, it is possible to formulate fault classification index (FI) by adding $\mathbf{H}$ terms corresponding to the "Fault

Table 1. Logic relation for asymmetrical fault
Type" in column as follows.

$$
\begin{aligned}
\mathrm{FI}_{\mathrm{a}-\mathrm{g}} & =\left(1-\mathrm{Z}_{\mathrm{Na}}(\mathrm{k})\right)+\mathrm{Z}_{\mathrm{Nb}}(\mathrm{k})+\mathrm{Z}_{\mathrm{Nc}}(\mathrm{k}) \\
\mathrm{FI}_{\mathrm{b}-\mathrm{g}} & =\left(1-\mathrm{Z}_{\mathrm{Nb}}(\mathrm{k})\right)+\mathrm{Z}_{\mathrm{Na}}(\mathrm{k})+\mathrm{Z}_{\mathrm{Nc}}(\mathrm{k}) \\
\mathrm{FI}_{\mathrm{c}-\mathrm{g}} & =\left(1-\mathrm{Z}_{\mathrm{Nc}}(\mathrm{k})\right)+\mathrm{Z}_{\mathrm{Na}}(\mathrm{k})+\mathrm{Z}_{\mathrm{bc}}(\mathrm{k}) \\
\mathrm{FI}_{\mathrm{ab}, \mathrm{ab}-\mathrm{g}} & =\left(1-\mathrm{Z}_{\mathrm{Na}}(\mathrm{k})\right)+\left(1-\mathrm{Z}_{\mathrm{Nb}}(\mathrm{k})\right)+\mathrm{Z}_{\mathrm{Nc}}(\mathrm{k}) \\
\mathrm{FI}_{\mathrm{ac}, \mathrm{ac}-\mathrm{g}} & =\left(1-\mathrm{Z}_{\mathrm{Na}}(\mathrm{k})\right)+\left(1-\mathrm{Z}_{\mathrm{Nc}}(\mathrm{k})\right)+\mathrm{Z}_{\mathrm{Nb}}(\mathrm{k}) \\
\mathrm{FI}_{\mathrm{bc}, \mathrm{bc}-\mathrm{g}} & =\left(1-\mathrm{Z}_{\mathrm{Nb}}(\mathrm{k})\right)+\left(1-\mathrm{Z}_{\mathrm{Nc}}(\mathrm{k})\right)+\mathrm{Z}_{\mathrm{Na}}(\mathrm{k})
\end{aligned}
$$

Where $F I$ is fault index and the subscript $a-g, b-g, c-g$, $a b, a b-g, a c, a c-g, b c$ and $b c-g$ denote the type of unsymmetrical fault. After obtaining the fault indices from the equations above, the new rules base can be formulated by using the fault classification index and can be explained according to flowchart in Fig. 3.

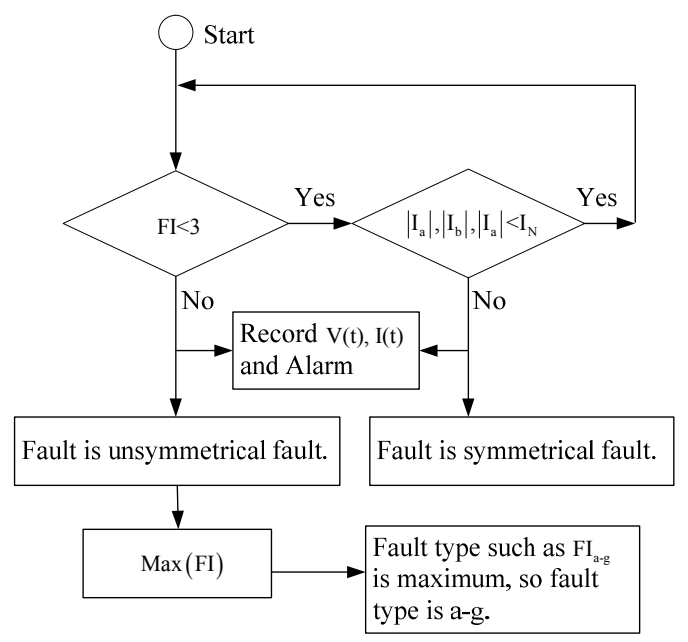

Fig. 3. Fault Detection and indentify type of fault.

If $\mathrm{FI}<3$ and $\left|\mathrm{I}_{\mathrm{a}}\right|,\left|\mathrm{I}_{\mathrm{b}}\right|,|\mathrm{I}|_{\mathrm{c}}<\mathrm{I}_{\mathrm{N}}$, distribution feeder is normal, where $I_{N}$ is a pick phase current.

If $\mathrm{FI}<3$ and $\left|\mathrm{I}_{\mathrm{a}}\right|,\left|\mathrm{I}_{\mathrm{b}}\right|,|\mathrm{I}|_{\mathrm{c}} \geq \mathrm{I}_{\mathrm{N}}$, the fault is symmetrical or three phase fault.

If $\mathrm{FI} \geq 3$, The fault is unsymmetrical and the maximum value of fault classification index in equation (20)-(25) are used to identify the type of asymmetrical fault. For an example, if $\mathrm{FI}_{\mathrm{a}-\mathrm{g}}$ is the maximum value and more than 3, the fault type is phase $a$ to ground fault.

\subsection{Fault Location Algorithm with Load Current Consideration}

One-ended method calculates a fault location from the apparent reactance seen by looking into the line from one end. In fact, the current that flows through the feeder consists of load and fault current as shown in Fig. 4.

Therefore, load current needs to be eliminated in the algorithms for distribution systems fault locations to reduce the error. When considering the effect of load, the apparent 


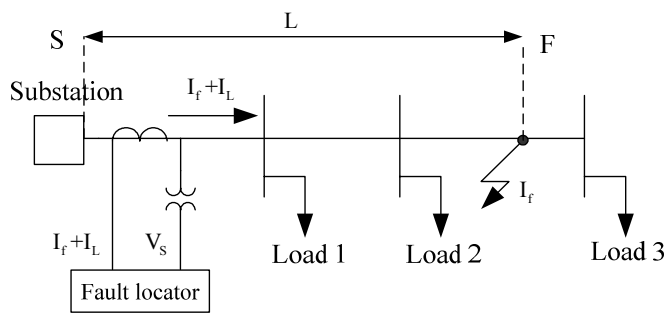

Fig. 4. Effects of the load current to evaluation the fault location.

impedance seen by looking into the line from the measuring point can be expressed by

$$
\frac{\mathrm{V}_{\mathrm{S}}}{\mathrm{I}_{\mathrm{f}}+\mathrm{I}_{\mathrm{L}}}=\mathrm{Z}_{\text {app }}=\mathrm{R}_{\text {app }}+\mathrm{j} \mathrm{X}_{\text {app }}
$$

Multiply (26) by $\left(\mathrm{I}_{\mathrm{f}}+\mathrm{I}_{\mathrm{L}}\right)$, then

$$
\mathrm{V}_{\mathrm{S}}=\mathrm{Z}_{\text {app }} \cdot \mathrm{I}_{\mathrm{f}}+\mathrm{Z}_{\text {app }} \cdot \mathrm{I}_{\mathrm{L}}
$$

Divide (27) by $I_{f}$, then

$$
\frac{V_{S}}{I_{f}}=Z_{a p p}\left(1+\frac{I_{L}}{I_{f}}\right)
$$

$\begin{array}{cl}\text { Where } & \\ \mathrm{I}_{\mathrm{f}} & \text { is the fault current. } \\ \mathrm{I}_{\mathrm{L}} & \text { is the load current during fault. } \\ \mathrm{Z}_{\text {app }} & \text { is the apparent impedance. } \\ \mathrm{R}_{\text {app }} & \text { is the apparent resistance. } \\ \mathrm{X}_{\text {app }} & \text { is the apparent reactance. } \\ \mathrm{I}_{\text {pre-fault }} & \text { is the pre-fault current. } \\ \mathrm{I}_{\text {during-fault }} & \text { is the during-fault current. }\end{array}$

Let assume that $\mathrm{I}_{\mathrm{L}} \approx \mathrm{I}_{\text {pre-fault }}$ and $\mathrm{I}_{\mathrm{f}} \approx \mathrm{I}_{\text {during-fault }}-\mathrm{I}_{\text {pre-fault }}$. Subsequently, the ratio of load current to fault current is estimated according to (29). This ratio is defined in this paper as the fault boundary factor $(\mathrm{K})$.

$$
\frac{\mathrm{I}_{\mathrm{L}}}{\mathrm{I}_{\mathrm{f}}} \approx \frac{\mathrm{I}_{\text {pre-fault }}}{\mathrm{I}_{\text {during-fault }}-\mathrm{I}_{\text {pre-fault }}}=\mathrm{K}
$$

Substitute K from(29) into (28), then

$$
\frac{\mathrm{V}_{\mathrm{S}}}{\mathrm{I}_{\mathrm{f}}}=\mathrm{Z}_{\mathrm{app}}(1+\mathrm{K})
$$

The errors of the fault distance are compensated by fault boundary factor $(\mathrm{K})$ in (30). The boundary of the faulted area can be determined between the starting point (SP) and the ending point (EP) as shown in Table 2. The apparent reactance $\left(\mathrm{X}_{\mathrm{app}}\right)$ is calculated from the imaginary part of

\begin{tabular}{|c|c|c|c|c|}
\hline $\begin{array}{l}\text { Fault } \\
\text { Type }\end{array}$ & $\mathrm{V}_{\text {select }}$ & $I_{\text {select }}$ & $\mathrm{SP}(\mathrm{km})$ & $\mathrm{EP}(\mathrm{km})$ \\
\hline a-g & $\mathrm{V}_{\mathrm{a}}$ & $I_{a}$ & \multirow{3}{*}{$\frac{X_{\text {app }}}{X_{s}}$} & \multirow{3}{*}{$\frac{X_{\text {app }} \cdot(1+K)}{x_{s}}$} \\
\hline b-g & $V_{b}$ & $\mathrm{I}_{\mathrm{b}}$ & & \\
\hline c-g & $\mathrm{V}_{\mathrm{c}}$ & $I_{c}$ & & \\
\hline $\begin{array}{c}\mathrm{ab}, \\
\mathrm{ab}-\mathrm{g}\end{array}$ & $V_{a}-V_{b}$ & $\mathrm{I}_{\mathrm{a}}-\mathrm{I}_{\mathrm{b}}$ & \multirow{3}{*}{$\frac{X_{\text {app }}}{X_{s}-X_{m}}$} & \multirow{4}{*}{$\frac{\mathrm{X}_{\mathrm{app}} \cdot(1+\mathrm{K})}{\mathrm{X}_{\mathrm{s}}-\mathrm{X}_{\mathrm{m}}}$} \\
\hline $\begin{array}{c}\text { ac, } \\
\text { ac-g }\end{array}$ & $V_{a}-V_{c}$ & $\mathrm{I}_{\mathrm{a}}-\mathrm{I}_{\mathrm{c}}$ & & \\
\hline $\begin{array}{c}\text { bc, } \\
\text { bc-g }\end{array}$ & $\mathrm{V}_{\mathrm{b}}-\mathrm{V}_{\mathrm{c}}$ & $I_{b}-I_{c}$ & & \\
\hline$a-b-c$ & & Same & to-phas & \\
\hline
\end{tabular}
the selected voltage $\left(\mathrm{V}_{\text {select }}\right)$ divided by the selected current ( $\mathrm{I}_{\text {select }}$ ) according to the fault type.
Table 2. The ratio of the selected voltage to the selected current

Where $x_{s}, x_{m}$ is self and mutual reactance of feeder line per kilometer.

In Table 2, the fault location was calculated from the imaginary part of the selected voltage $\left(\mathrm{V}_{\text {select }}\right)$ divided by the selected current $\left(\mathrm{I}_{\text {select }}\right)$ according to the fault type such as example a single line to ground fault in phase a, then $\mathrm{V}_{\text {select }}=\mathrm{V}_{\mathrm{a}}$ and $\mathrm{I}_{\text {select }}=\mathrm{I}_{\mathrm{a}}$. Phase quantities are easier to understand when one has to calculate fault location. Assume the power system has been reduced to a three phase thevenin equivalent circuit, seen from the fault location, with the matrix equation.

$$
\left[\begin{array}{c}
\mathrm{V}_{\mathrm{a}} \\
\mathrm{V}_{\mathrm{b}} \\
\mathrm{V}_{\mathrm{c}}
\end{array}\right]=\mathrm{L} \cdot\left[\begin{array}{ccc}
\mathrm{z}_{\mathrm{s}} & \mathrm{Z}_{\mathrm{m}} & \mathrm{Z}_{\mathrm{m}} \\
\mathrm{z}_{\mathrm{m}} & \mathrm{Z}_{\mathrm{s}} & \mathrm{Z}_{\mathrm{m}} \\
\mathrm{Z}_{\mathrm{m}} & \mathrm{Z}_{\mathrm{m}} & \mathrm{Z}_{\mathrm{s}}
\end{array}\right] ?\left[\begin{array}{c}
\mathrm{I}_{\mathrm{a}} \\
\mathrm{b} \\
\mathrm{I}_{\mathrm{c}}
\end{array}\right]
$$

Where $V_{a}, V_{b}, V_{c}$ are voltage phasor quantities, $I_{a}, I_{b}, I_{c}$ are current phasor quantities, $\mathrm{z}_{\mathrm{s}}$ and $\mathrm{z}_{\mathrm{m}}$ are the self and mutual impedances per kilometer in phase quantities and $\mathrm{L}$ is fault location. For the example a single line to ground fault in phase $a$, one simply sets $I_{b}=0$ and $I_{c}=0$. The fault location which uncompensated by fault boundary factor then becomes.

$$
\operatorname{imag}\left(\frac{V_{a}}{I_{a}}\right)=\operatorname{imag}\left(z_{s} \cdot L\right)
$$

Replace the term of $\operatorname{imag}\left(\frac{V_{a}}{I_{a}}\right)$ by apparent reactance $\left(X_{\text {app }}\right)$ and the term of $\operatorname{imag}\left(z_{s} \cdot L\right)$ by $\operatorname{imag}\left(x_{s} \cdot L\right)$ then

$$
\mathrm{L}=\frac{\mathrm{X}_{\mathrm{app}}}{\mathrm{X}_{\mathrm{s}}}
$$

Also, the phase to phase fault, the phase to phase to ground fault and three phase fault are easy to find from (34). 


$$
\mathrm{L}=\frac{\mathrm{X}_{\text {app }}}{\mathrm{X}_{\mathrm{s}}-\mathrm{X}_{\mathrm{m}}}
$$

The error of the fault location (L) from effect of load current in (33) and (34) are compensated by fault boundary factor $(K)$ in (30). So, the boundary of the faulted area can be summarized in Table 2.

\section{Implementation and Field Test Results}

Automated distribution system fault locator developed by using the techniques described above is presented in Fig. 5. The data acquisition system based on personal computer is composed of an analog to digital converter (A/D) with sampling rate at 16 samples per cycle. This $\mathrm{A} / \mathrm{D}$ digit is 16 bits with anti-aliasing RC filter of cut off frequency 1.0 $\mathrm{kHz}$. The current signal is delivered to the data acquisition system from a 600/5 A current transformer.

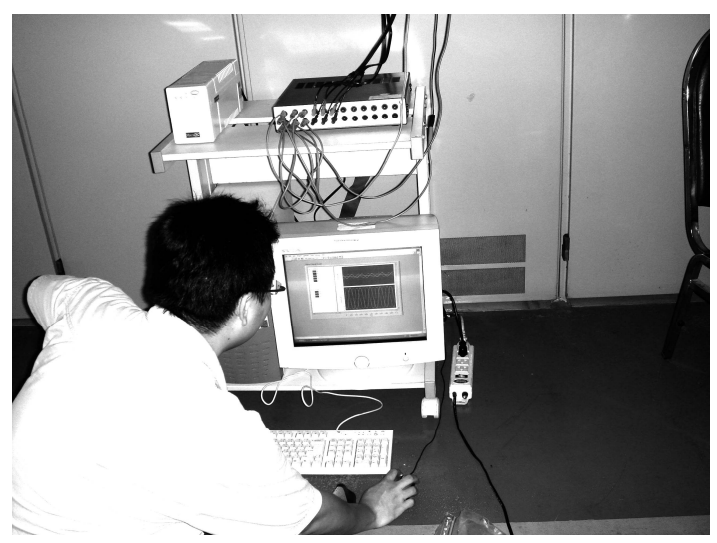

Fig. 5. Automate distribution system fault locator.

In order to evaluate the performance of the developed system, field tests have been conducted on several distribution feeders. The paper uses a power distribution at Phuket as an example to show the performance of the proposed method.

Case1: The operating voltage of Phuket's distribution system is $33 \mathrm{kV}, 50 \mathrm{~Hz}$. The actual fault location was at 3.25 $\mathrm{km}$ in the main feeder. Fig.5 (Check figure and table number again) illustrates the fault current-voltage and the digital signal for fault detection and type identification according to Fig.6. According to the waveforms, the faults started on phase a-b. Afterward, in less than half a cycle, the fault changed into phase c-a. It is obvious that the algorithm can correctly detect and identify the type of fault.

The apparent reactance is the imaginary part of the selected voltage phasor divided by the selected current phasor according to the type of fault. Adaptive algorithm was used to track/estimate the selected voltage and current phasor quantities and the apparent reactance as shown in Fig. 7. It is apparent that the new adaptive algorithm can effectively calculate the phasor quantities though the magnitude of each component changed.
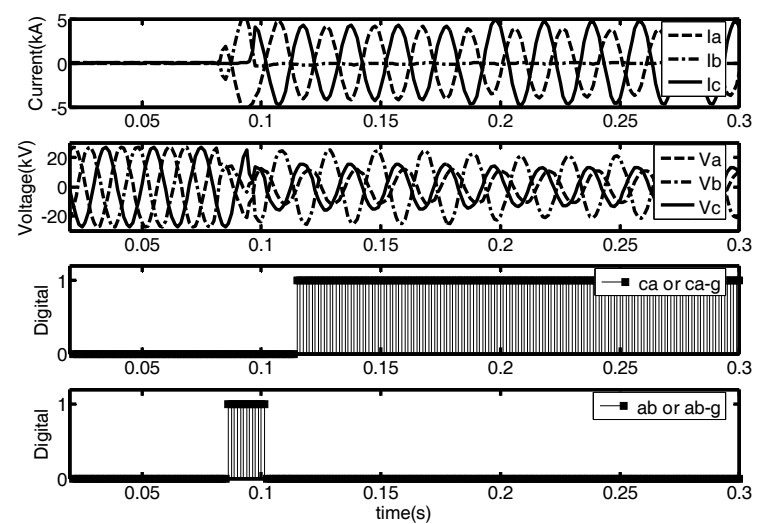

Fig. 6. Current-voltage signal and digital signal for fault detection and type identification.
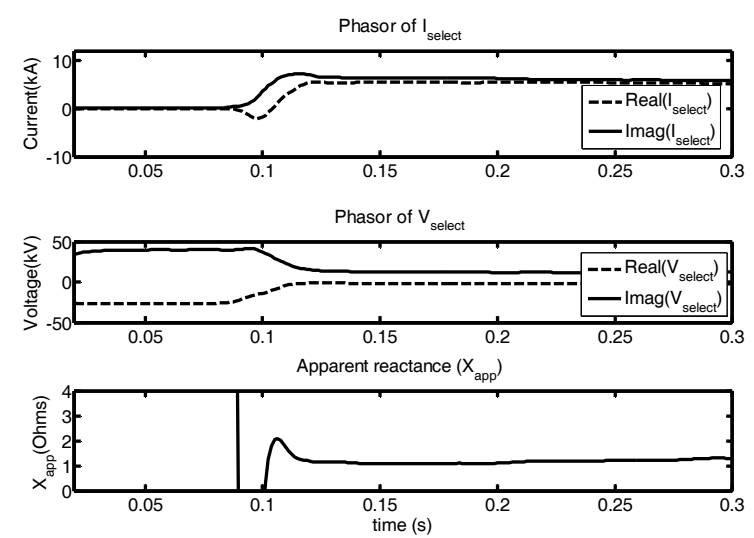

Fig. 7. Current-voltage phasor and apparent reactance.

All parameters for determining the position of fault were reported by automated distribution system fault locator. The parameters are initial fault type, fault type on steadystate, pre-fault current phasor quantities $\left(\mathrm{I}_{\text {pre-fault }}\right)$, select voltage phasor quantities $\left(\mathrm{V}_{\text {select }}\right.$ ), select current phasor quantities $\left(\mathrm{I}_{\text {select }}\right)$, apparent reactance $\left(\mathrm{X}_{\text {app }}\right)$, fault boundary factor $(\mathrm{K})$, self reactance of line per kilometer $\left(\mathrm{x}_{\mathrm{s}}\right)$, mutual reactance of line per kilometer $\left(\mathrm{x}_{\mathrm{m}}\right)$, start point of finding (SP) and end point of finding (EP). The parameters can be summarized in Table 3 .

When considering the effect of the load current, the boundary of faulted area is calculated. The reactance of the fault is compensated by $\mathrm{K}=0.01$ factor in Table 3. The estimated error boundary around the calculated fault location can be obtained by searching the network in outward direction from the source. The actual fault location is at AP $=3.25 \mathrm{~km}$ in the main feeder. The algorithm estimate the fault location to be located from $\mathrm{SP}=3.24 \mathrm{~km}$ to $\mathrm{EP}=3.27$ $\mathrm{km}$. Accordingly, the possible fault location areas are mapped on the geographic information system (GIS) as shown in Fig. 8. 
Table 3. The parameters for determining the position of fault

\begin{tabular}{c|c}
\hline Type of fault $($ initial $)$ & $\mathrm{a}-\mathrm{b}$ \\
\hline Type of fault $($ on steady-state $)$ & $\mathrm{a}-\mathrm{c}$ \\
\hline $\mathrm{I}_{\text {pre-fault }}($ at $\mathrm{t}=0.05 \mathrm{~s}$ of Fig. 7.$)$ & $-24.86+\mathrm{j} 90.65 \mathrm{~A}$ \\
\hline $\mathrm{I}_{\text {select }}=($ at $\mathrm{t}=0.15$ s of Fig. 7.) & $5429.93+\mathrm{j} 6299.64 \mathrm{~A}$ \\
\hline $\mathrm{V}_{\text {select }}=($ at $\mathrm{t}=0.15 \mathrm{~s}$ of Fig. 7.$)$ & $-1679.31+\mathrm{j} 12040.92 \mathrm{~V}$ \\
\hline $\mathrm{X}_{\text {app }}=\operatorname{imag}\left(\mathrm{V}_{\text {select }} / \mathrm{I}_{\text {select }}\right)$ & $1.10 \mathrm{Ohms}$ \\
\hline $\mathrm{K}=\mathrm{abs}\left(\mathrm{I}_{\text {pre-fault }} / \mathrm{I}_{\text {select }}\left(-\mathrm{I}_{\text {pre-fault }}\right)\right.$ & 0.01 \\
\hline $\mathrm{x}_{\mathrm{s}}(\mathrm{see}$ as appendix $)$ & $0.74 \mathrm{Ohms} / \mathrm{km}$ \\
\hline $\mathrm{x}_{\mathrm{m}}(\mathrm{see}$ as appendix $)$ & $0.40 \mathrm{Ohms} / \mathrm{km}$ \\
\hline $\mathrm{SP}=\frac{\mathrm{X}_{\mathrm{s}}-\mathrm{x}_{\mathrm{m}}}{2}=\frac{1.10}{0.74-0.4}$ & $3.24 \mathrm{~km}$ \\
\hline $\mathrm{EP}=\frac{\mathrm{X}_{\text {app }} \cdot(1+\mathrm{K})}{\mathrm{x}_{\mathrm{s}}-\mathrm{x}_{\mathrm{m}}}=\frac{1.10 \cdot(1+0.01)}{0.74-0.4}$ & $3.27 \mathrm{~km}$ \\
\hline
\end{tabular}

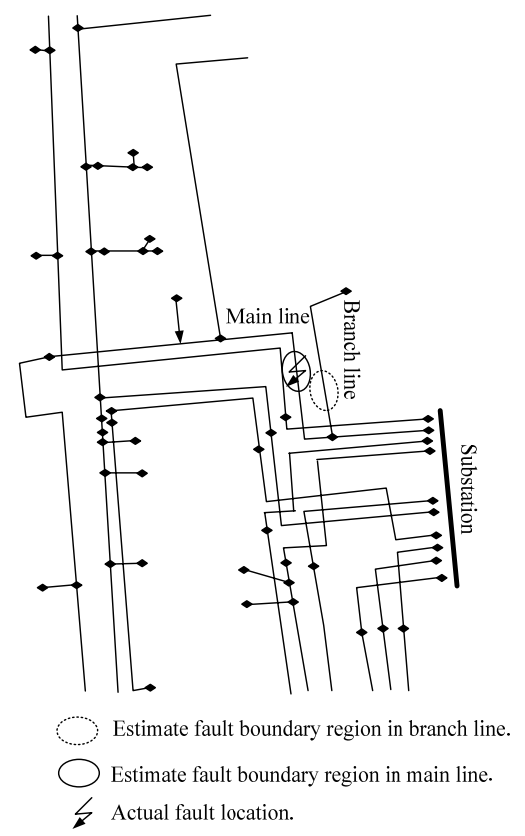

Fig. 8. Fault location results in GIS.

Case2: The actual fault location was at $7.0 \mathrm{~km}$ in the main feeder. Fig. 9 illustrates the fault current-voltage and
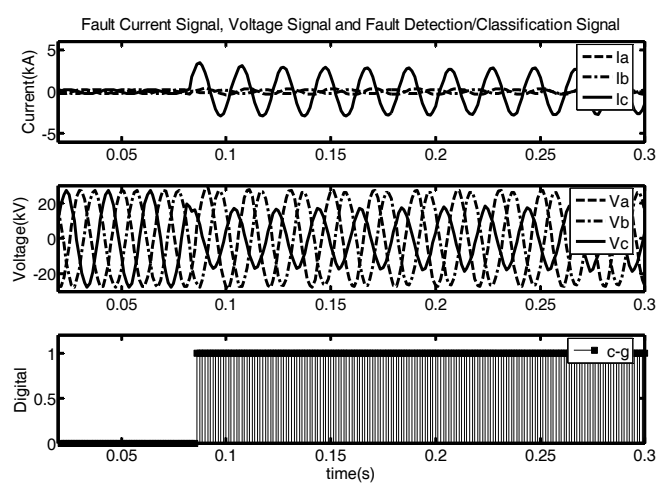

Fig. 9. Current-voltage signal and digital signal for fault detection and type identification. digital signal for fault detection and type identification. According to the waveforms, the faults started on phase c-g.

The selected current-voltage phasor quantities and the apparent reactance are shown in Fig. 10.
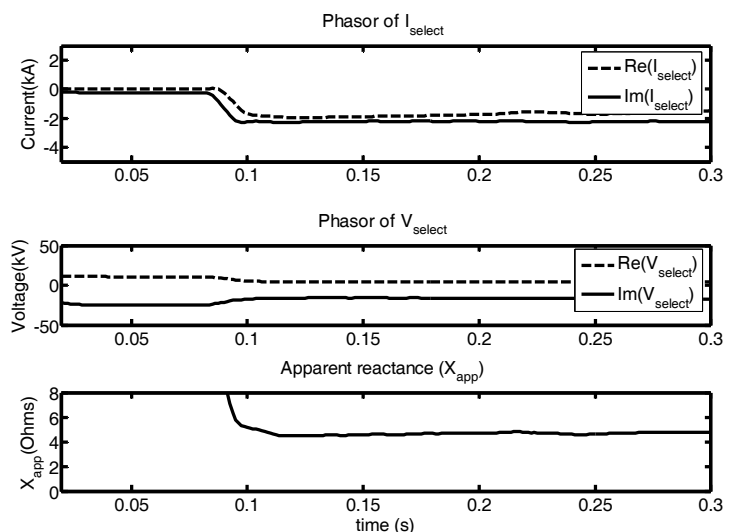

Fig. 10. Current-voltage phasor and apparent reactance.

All parameters for determining the position of fault are summarized in Table 4.

Table 4. The parameters for determining the position of fault.

\begin{tabular}{c|c}
\hline Type of fault (on steady-state) & $\mathrm{c}-\mathrm{g}$ \\
\hline $\mathrm{I}_{\text {pre-fault }}($ at $\mathrm{t}=0.05 \mathrm{~s}$ of Fig 10.$)$ & $7.64+\mathrm{j} 250.47 \mathrm{~A}$ \\
\hline $\mathrm{I}_{\text {select }}=($ at $\mathrm{t}=0.15 \mathrm{~s}$ of Fig 10.) & $-1113.23+\mathrm{j} 2200.10 \mathrm{~A}$ \\
\hline $\mathrm{V}_{\text {select }}=($ at $\mathrm{t}=0.15 \mathrm{~s}$ of Fig 10.$)$ & $4300.73-\mathrm{j} 18426.84 \mathrm{~V}$ \\
\hline $\mathrm{X}_{\text {app }}=\mathrm{imag}\left(\mathrm{V}_{\text {select }} / \mathrm{I}_{\text {select }}\right)$ & $4.93 \mathrm{Ohms}$ \\
\hline $\mathrm{K}=\mathrm{abs}\left(\mathrm{I}_{\text {pre-fault }} /\left(\mathrm{I}_{\text {select }}-\mathrm{I}_{\text {pre-fault }}\right)\right)$ & 0.11 \\
\hline $\mathrm{x}_{\mathrm{s}}($ see as appendix $)$ & $0.74 \mathrm{Ohms} / \mathrm{km}$ \\
\hline $\mathrm{x}_{\mathrm{m}}(\mathrm{see}$ as appendix $)$ & $0.40 \mathrm{Ohms} / \mathrm{km}$ \\
\hline $\mathrm{SP}=\frac{\mathrm{X}_{\text {app }}}{\mathrm{x}_{\mathrm{s}}}=\frac{4.93}{0.74}$ & $6.66 \mathrm{~km}$ \\
\hline $\mathrm{EP}=\frac{\mathrm{X}_{\text {app }} \cdot(1+\mathrm{K})}{\mathrm{x}_{\mathrm{s}}}=\frac{4.93 \cdot(1+0.11)}{0.74}$ & $7.40 \mathrm{~km}$
\end{tabular}

The actual fault location at $\mathrm{AP}=7.0 \mathrm{~km}$ in the main feeder. The algorithm estimate the fault location to be located from $\mathrm{SP}=6.66 \mathrm{~km}$ to $\mathrm{EP}=7.40 \mathrm{~km}$.

Table 5 presents field test results for six cases in Phuket. As one can see, the entire actual fault points (AP) lie within the starting point (SP) and ending point (EP).

Table 5. Summary of field test results

\begin{tabular}{c|c|c|c|c|c}
\hline \multirow{2}{*}{ Case } & \multirow{2}{*}{$\begin{array}{c}\text { Fault } \\
\text { type }\end{array}$} & $\begin{array}{c}\text { Start } \\
\text { point to } \\
\text { finding }\end{array}$ & $\begin{array}{c}\text { End } \\
\text { point to } \\
\text { finding }\end{array}$ & $\begin{array}{c}\text { Actual fault } \\
\text { location }\end{array}$ & \multirow{2}{*}{$\begin{array}{c}\text { Error } \\
(\%)\end{array}$} \\
\cline { 3 - 5 } & SP (km) & EP (km) & AP (km) & \\
\hline 1 & $\begin{array}{c}\text { a-b/ } \\
\text { a-c }\end{array}$ & 3.24 & 3.27 & 3.25 & 0.31 \\
\hline 2 & c-g & 6.66 & 7.40 & 7.00 & 4.86 \\
\hline 3 & b-c & 7.73 & 8.25 & 8.00 & 3.37 \\
\hline 4 & c-g & 3.70 & 3.85 & 3.75 & 1.33 \\
\hline 5 & a-g & 4.09 & 4.32 & 4.20 & 2.62 \\
\hline 6 & $\begin{array}{c}\text { b-g/ } \\
\text { b-c }\end{array}$ & 6.48 & 6.77 & 6.50 & 0.31 \\
\hline
\end{tabular}


The percent of error of the fault location is calculated by the following equation.

$$
\% \text { Error }=\frac{|\mathrm{SP}-\mathrm{AP}|}{\mathrm{AP}} ? 00
$$

Where

SP is start point to finding fault.

AP is actual point to finding fault.

\section{Conclusion}

This work presents a complete algorithm to detect, identify, and locate all fault types on power distribution feeders. The field test results prove the robustness and performance of the algorithm and encourage for practical use with promising result. The errors from field test results are within $5 \%$. Consequently the service restoration process will also be significantly sped up.

Several benefits can be obtained by using the proposed algorithm. The method helps decrease the time spent by maintenance crews for locating the fault considerably, from 4-5 hours to approximately 1 hour per case in daytime and from 8-12 hours to approximately 2 hours per case during nighttime. As a result, reliability of the distribution system improves. Furthermore, fast and accurate estimation of the fault location can help speed up crew work and reduce the total number of stand by crews Cost of operational maintenance and supply interruptions are also reduced. Consequently, utility will receive a good feed-back from the crews and customers.

\section{Discussion and Future Work}

Short duration faults or transient faults are fault that can self cleared in half a cycle to one cycle as shown in Fig.11.

The algorithm in this paper available for locate permanent faults, it may be too short time when short duration faults in haft a cycle. Because adaptive algorithm that used to track voltage-current phasor need about one cycle of signal to extract voltage-current phasor. The identification

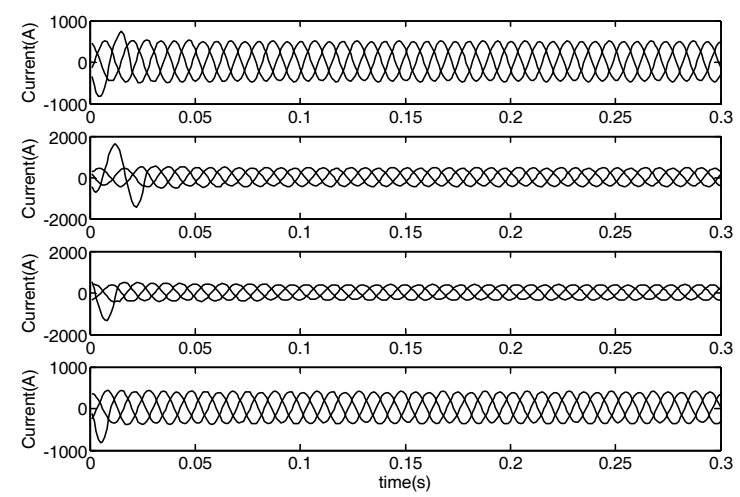

Fig. 11. Actual record waveform of short duration fault. of particular areas with a high number of short duration faults makes it possible to corrective maintenance work such thermal vision patrol or tree trimming. So, in future work, we would like to design the algorithm that can indentify areas with a high number of short duration faults is distribution system.

\section{Appendix}

Distribution-line data is radial system.

Frequency $=50 \mathrm{~Hz}$.

Operating voltage $=33 \mathrm{kV}$.

System ground is solidly ground.

Main line is partial insulation conductor 185 sq.mm.

Self impedance $\mathrm{z}_{\mathrm{s}}=0.27+0.74 \mathrm{i} \mathrm{Ohms} / \mathrm{km}$.

Mutual impedance $\mathrm{z}_{\mathrm{m}}=0.06+0.40 \mathrm{i} \mathrm{Ohms} / \mathrm{km}$.

Self reactance $\mathrm{z}_{\mathrm{s}}=0.74 \mathrm{Ohms} / \mathrm{km}$.

Mutual reactance $\mathrm{z}_{\mathrm{m}}=0.40 \mathrm{Ohms} / \mathrm{km}$.

\section{Acknowledgments}

The authors acknowledge would like to thank the Research Division of Provincial Electricity Authority Thailand (PEA) for their support this project. Also, the authors wish to extend their thanks to my advisor Asst. Prof. Dr. Teratum Bunyagul, operators and crews at Phuket's substation for support the field tests. This work is thesis submitted to the faculty of King Mongkut's University of Technology North Bangkok Thailand for the degree of PhD in electrical engineering.

\section{References}

[1] Takagi, T.; Yamakoshi, Y.; Baba, J.; Uemura, K.; and Sakaguchi, T. 1982. A New Algorithm of an Accurate Fault Location for EHVKJHV Transmission-line s. IEEE Trans. Power Apparatus and Systems. Vol.PAS101, No.3, pp.564-573.

[2] Takagi, T.; Jamakoshi, T.; Yamaura, M.; Kondow, R.; and Matshusima, T. 1982. Development of a new type fault locator using one-terminal voltage and current data. IEEE Trans. Power App. Syst. Vol.PAS-101, pp.2892-2898.

[3] Sant, and Paithankar, Y. 1979. On-line digital fault locator for overhead transmission-line . IEEE Proceedings. Vol.126, No.11, pp.1181-1185.

[4] Lehtonen, M.; Pettissalo, S. and Etula, J. H. 1991. Calculational fault location for electrical distribution networks. In Proc. 3rd Int. Conf. Power System Monitoring and Control. London, U.K., pp.38 -43.

[5] Tenschert, W. 1993 Fault location using fault distance measurement of digital relays. In Proc. 12th Int. Conf. Electricity Distribution. CIRED, London, U.K., 
pp.4.20.1-4.

[6] Jarventausta, P. 1998. Using Fuzzy Sets to Fault Location in Distribution Networks. Physica Verlac. New York.

[7] Johns, A. T.; Lai, L.L.; El-Hami, M. and Daruvala, D. J. 1993. New approach to directional fault location for overhead power distribution feeders. In Proc. Inst. Elect. Eng. C, Gen., Transm., Distrib. Vol.138, No.4, pp.38-43.

[8] Wattanasakpubal, C. and Bunyagul, T. 2005. Estimation and Tracking Current Phasor, Voltage Phasor, Impedance and Local Frequency in Power Systems by Adaptive Algorithm. In Proceedings of the Electrical Engineering Conference (EECON-28). Thailand, 20-21 October.

[9] Wattanasakpubal, C. and Bunyagul, T. 2008. A processing unit for tracking/estimating voltage-current phasor and frequency in power system. In Proceedings of the Electrical Engineering/Electronics, Computer, Telecommunications and Information Technology, International Conference 5th (ECTI-CON). Thailand, Vol.2, 14-17 May, pp.1061-1064.

[10] Wattanasakpubal, C. and Bunyagul, T. 2007. Design Algorithm for Detection, Identification and Fault Location on Inhomogeneous Distribution Feeders. In Proceedings of Advance Power System Automation and Protection (APAPA 2007). Korea, 24-27 April.

[11] Wattanasakpubal, C. and Bunyagul, T. 2008. Design of an algorithm for detecting, identifying and locating on inhomogeneous distribution feeders. In Proceedings of Developments in Power System Protection $9^{\text {th }}$ (DPSP) International Conference. Glasgow, U.K., 17-20 March, pp.626-631.

[12] Zhu, J.; Lubkeman, D. L. and Girgis, A. 1997. Automated fault location and diagnosis on electric power distribution feeders. IEEE Trans. Power Del. Vol.12, pp.801-809.

[13] Jarventausta, P.; Verho, P. and Partanen, J. April 1994. Using Fuzzy Sets to Model the Uncertainty in the Fault Location Process of Distribution Networks. IEEE Transactions on Power Delivery. Vol.9, No.2, pp.954-960.

[14] Girgis, A. A. and Johns, M. B. April 1989. A Hybrid Expert System for Faulted Section Identification, Fault Type Classification and Selection of Fault Location Algorithms. IEEE Transactions on Power Deliver. Vol.4, No.2., pp.978-985.
[15] Yuan-Yih Hsu; Lu, F.C.; Chien, Y.; Liu, J.P.; Lin, J. T.; Yu, P.H.S. and Kuo, R.R.T. January 1992. An Expert System for Locating Distribution System Faults. IEEE Transactions on Power Delivery. Vol.6, No.1, pp.336-372.

[16] William Stevenson. 1983. Element of Power System Analysis, $4^{\text {th }}$ Ed., McGraw-Hill.

[17] Anderson, P.M., 1995. Analysis of Faulted Power Systems, IEEE Press, Piscataway, NJ.

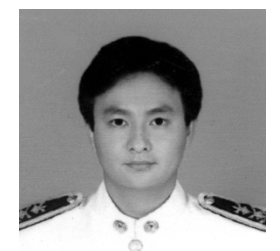

Choowong-Wattanasakpubal He was born in Songkhla, Thailand, on March 5, 1976. He received bachelor and master degree in Electrical Engineering from King Mongkut's Institute of Technology North Bangkok, Bangkok, Thailand in 1999 and 2003, respectively. $\mathrm{He}$ is studying Ph.D. degree at Electrical Engineering at King Mongkut's University of Technology North Bangkok. Currently, he is an Assistant Chief of Power Analysis Section at Research Division of Provincial Electricity Authority Thailand (PEA). His main fields of research are power system protection, fault location, grounding and digital signal processing (DSP) application to power system.

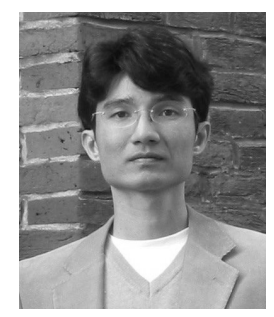

Teratam Bunyagul He was born in Phattalung, Thailand, on 1974. He received bachelor degree in Electrical Engineering from King Mongkut's Institute of Technology North Bangkok. He received master degree in Electrical Engineering from University of Manchester Institute of Science and Technology, UK. He received the Ph.D. in Electrical Engineering from University of Manchester Institute of Science and Technology, UK. Currently, he is an Assistant Professor in the Department of Electrical Engineering at King Mongkut's University of Technology North Bangkok. He has consulted widely with government agencies and the electrical industry. His main fields of research are Power systems protection, automation system and digital signal processing (DSP) application to power system. 